\title{
Deposition of SiO Thin Films on Y-TZP by Reactive Magnetron Sputtering: Influence of Plasma Parameters on the Adhesion Properties Between Y-TZP and Resin Cement for Application in Dental Prosthesis
}

\author{
José Renato Calvacanti de Queiroza, Diego Alexandre Duarte ${ }^{\mathrm{b}}$, Rodrigo Othávio de Assunção e Souzac, \\ Sara Fernanda Fissmer ${ }^{\mathrm{b}}$, Marcos Massi ${ }^{\mathrm{b}}$, Marco Antonio Bottino ${ }^{\mathrm{a}}$ \\ ${ }^{a}$ School of Dentistry, São Paulo State University - UNESP, \\ CEP 12245-000, São José dos Campos, SP, Brazil \\ ${ }^{\mathrm{b}}$ Plasma Science and Technology Laboratory, Technological Institute of Aeronautics - ITA, \\ CEP 12228-900, São José dos Campos, SP, Brazil \\ ${ }^{c}$ Department of Restorative Dentistry, Federal University of Paraíba - UFPB, \\ CEP 58039-080, João Pessoa, PB, Brazil
}

Received: December 23, 2010; Revised: April 30, 2011

\begin{abstract}
In this paper $\mathrm{SiO}_{\mathrm{x}}$ thin films were deposited on $\mathrm{Y}$-TZP ceramics by reactive magnetron sputtering technique in order to improve the adhesion properties between Y-TZP and resin cement for applications in dental prosthesis. For fixed cathode voltage, target current, working pressure and target-to-substrate distance, $\mathrm{SiO}_{\mathrm{x}}$ thin films were deposited at different oxygen concentrations in the $\mathrm{Ar}+\mathrm{O}_{2}$ plasma forming gas. After deposition processes, $\mathrm{SiO}_{x}$ thin films were characterized by profilometry, energy dispersive spectroscopy (EDS), optical microscopy and scanning electron microscopy (SEM). Adhesion properties between Y-TZP and resin cement were evaluated by shear testing. Results indicate that films deposited at $20 \% \mathrm{O}_{2}$ increased the bond strength to (32.8 \pm 5.4$) \mathrm{MPa}$. This value has not been achieved by traditional methods.
\end{abstract}

Keywords: Y-TZP, dental material, thin films, silicon oxide

\section{Introduction}

Ytria-stabilized tetragonal-zirconia-polycrystalline (Y-TZP) is a biocompatible material that has excellent mechanical properties, such as, high flexural strength, fracture toughness and phase transformations through the stress generated in the appearance of cracks $^{1,2}$. Since the first appearance of Y-TZP as dental material, it has been increasingly used as infrastructure for metal-free prosthesis ${ }^{3}$, however the lack of chemical interaction between resin cement and zirconia surface decreases the bond strength. Good adhesion mediated by the use of resin-based cement in this interface is important for high retention, prevention of microleakage in this interface and to increase fracture and fatigue resistances to all-ceramic crowns ${ }^{6}$. Many surface treatments have been suggested in order to improve the bond strength between Y-TZP and resin cement as, for example, air particle abrasion with $\mathrm{Al}_{2} \mathrm{O}_{3}$ associated with the use of primers that contain adhesive monomers (4-methacryloxyethyl trimellitate anhydride or methacryloxy decyl phosphoric acid monomers) or tribochemical $\mathrm{SiO}_{2}$ coating associated to silane coupling agent application ${ }^{4}$. Both surface treatments improve the bond strength between Y-TZP and resin cement ${ }^{5-7}$. However, the impact of particles can induce tetragonal to monoclinic phase change on the zirconia surface. This region may contain microcracks and other flaws that could compromise long-term durability of Y-TZP ${ }^{7-11,14}$, which lead us to seek another method in order to provide a reliable bond strength between these two materials without damage the Y-TZP surface for ensuring longevity with clinical success of zirconia-based prosthetic restorations.

Reactive magnetron sputtering deposition ${ }^{12,13}$ is a plasma technique that presents as an efficient tool to be used in such applications once the bombardment of high-energy particles on solid surfaces creates free radicals, which may be useful to increase the adhesion properties between two different materials without compromise the surface of the substrate. Thus, as the chemical modification of Y-TZP by plasma processing is not well understood, in this work reactive magnetron sputtering was used to deposit $\mathrm{SiO}_{\mathrm{x}}$ thin films on Y-TZP ceramics aiming to facilitate the adhesion properties between Y-TZP and resin cement.

\section{Experimental Setup}

Y-TZP ceramics with $15 \mathrm{~mm}$ in diameter and $1.2 \mathrm{~mm}$ in thickness were sinterized at $1500{ }^{\circ} \mathrm{C}$, polished and ultrasonically cleaned for 5 minutes in de-ionized water. Experiments were carried out in a vacuum chamber (schematically shown in Figure 1) evacuated to a background pressure of $5.0 \times 10^{-5}$ Torr $\left(\sim 0.7 \times 10^{-3} \mathrm{~Pa}\right)$. Cathode voltage, target current, working pressure and target-to-substrate distance $\left(d_{\mathrm{ts}}\right)$ were fixed at $(500 \pm 5) \mathrm{V},(0.50 \pm 0.05) \mathrm{A},(20 \pm 1)$ mTorr $(\sim 2.7 \mathrm{~Pa})$ and $(48 \pm 1) \mathrm{mm}$, respectively. As sputtering source a silicon target $(99.999 \%)$ was used and $\mathrm{SiO}_{\mathrm{x}}$ thin films were deposited on Y-TZP at 20, 40 and 60\% $\mathrm{O}_{2}$ in $\mathrm{Ar}+\mathrm{O}_{2}$ gas mixture. During deposition processes, all substrates attained at maximum $105^{\circ} \mathrm{C}$. After deposition processes, films were analyzed by optical profilometry (Veeco Wyko NT 1100), optical microscopy (Mitutoyo MF-A), electron dispersive spectroscopy (EDS), scanning electron microscopy (SEM) (LEO $435 \mathrm{VPi}$ and Zeiss DSM 950) and by a universal testing machine (EMIC DL-100). Films thicknesses were measured by optical 


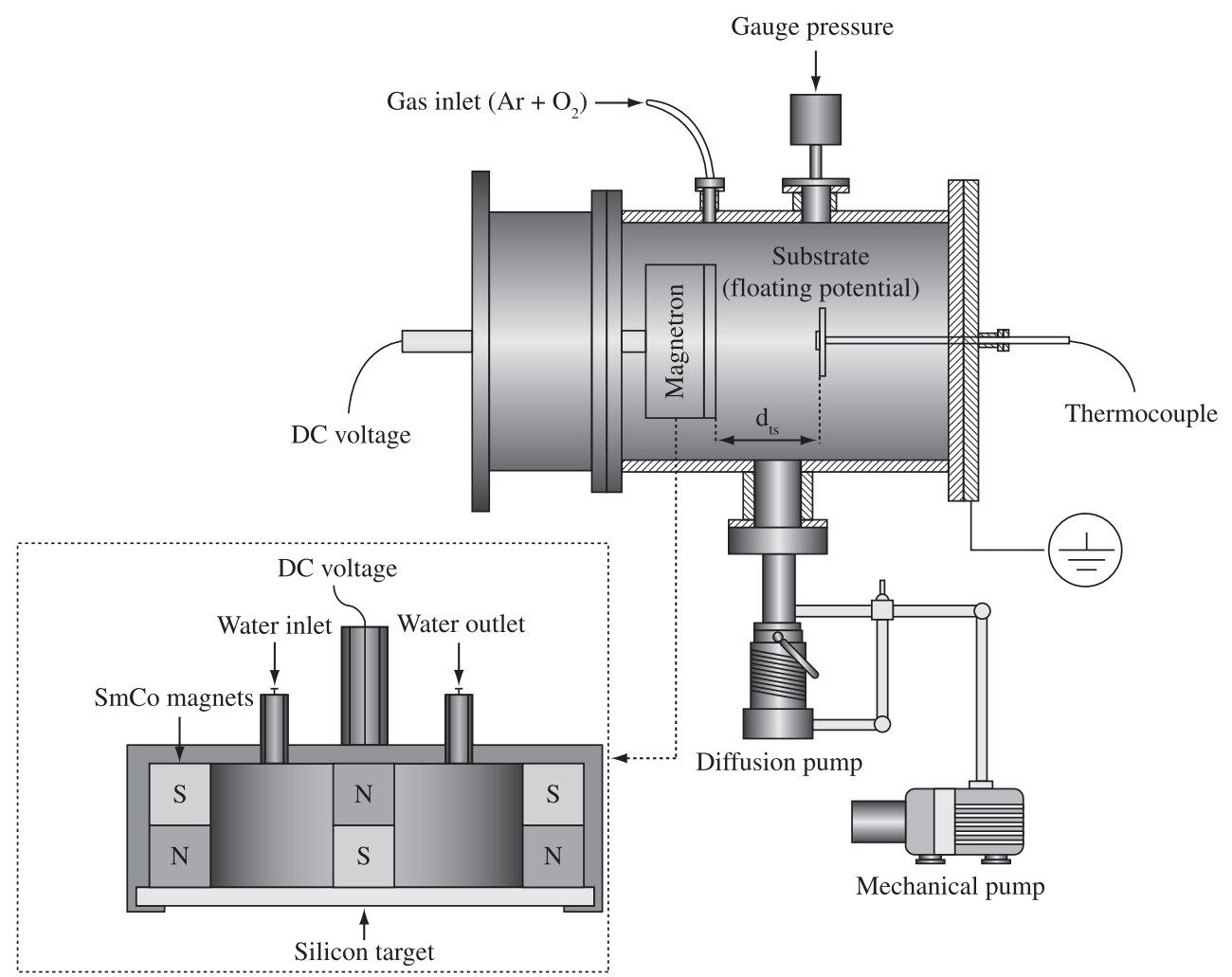

Figure 1. Experimental system used to deposition process.

profilometry (optical interference microscopy) in order to calculate the deposition rate that was done by taking the ratio between film thickness and deposition time (30 minutes). Also, optical profilometry was employed in order to analyze the surface topography through digital images and the roughness mean value $\left(\mathrm{R}_{\mathrm{a}}\right)$ of deposited films. The adhesion properties between Y-TZP ceramic and resin cement were studied as described schematically in Figure 2. The bonding agent 3-methacryloxypropyl trimethoxysilane was applied on $\mathrm{SiO}$ for curing for 180 seconds (step 2 in Figure 2). The bonding area of each sample was limited by an adhesive tape with $2.3 \mathrm{~mm}$ in hole diameter (step 3). The resin cement was placed into the transparent plastic cylinders $(2.3 \mathrm{~mm}$ in diameter and $3.0 \mathrm{~mm}$ in thickness) and, then, both were fixed on the 3-methacryloxypropyl trimethoxysilane (steps 4 and 5). After this process, samples were stored into de-ionized water at room temperature $\left(37^{\circ} \mathrm{C}\right)$ for self-curing for 48 hours (step 6). After removing the plastic cylinder (step 7), the shear bond strength test was performed by application of a $50 \mathrm{kgf}$ load-cell on the ceramic-cement interface in a speed of $1.0 \mathrm{~mm} / \mathrm{min}$ (step 8). After shear testing, fractured samples were analyzed by optical microscopy and scanning electron microscopy. In addition, other sample without $\mathrm{SiO}_{\mathrm{x}}$ was made in order to compare the bond strength with those that use $\mathrm{SiO}_{\mathrm{x}}$ as intermediate adhesive layer.

\section{Results and Discussion}

\subsection{Profilometry}

As shown in Figure 3, deposition rate of $\mathrm{SiO}_{x}$ thin films decreases from approximately 30 to $5 \mathrm{~nm} / \mathrm{min}$ as the oxygen concentration in the gas discharge increases from 20 to $60 \%$. This effect is caused by the well-known process of target poisoning (oxidation) that decreases the sputtering yield of the target and, as consequence, the condensing atom flux toward the Y-TZP ceramic surface. According to Hattum et al. ${ }^{15}$ as the oxygen flow rate increases, the gas discharge is characterized by a suddenly decrease of silicon atoms toward the growing film and, at the same time, $\mathrm{SiO}_{\mathrm{x}}$ molecules is increased, which indicates the covering of target and substrate by compound. Further, results indicate that surface roughness was not significantly modified as the oxygen concentration in the gas discharge increases. The roughness mean value of the films was found to be $(357 \pm 61) \mathrm{nm}$, $(391 \pm 69) \mathrm{nm}$ and $(366 \pm 73) \mathrm{nm}$ at 20,40 and $60 \% \mathrm{O}_{2}$, respectively. The roughness mean value of the Y-TZP surface without $\mathrm{SiO}_{x}$ film is $(380 \pm 32) \mathrm{nm}$. Then, one can conclude that no significant modifications in $\mathrm{R}_{\mathrm{a}}$ were observed once these values are much smaller than those achieved by sandblasting technique ${ }^{16}$.

\subsection{Energy dispersive spectroscopy (EDS)}

Silicon oxide is a wide band gap material $(9.0 \mathrm{eV})$ thereby it is transparent when deposited on Y-TZP. Thus, in order to confirm the presence of silicon on the substrates, EDS analyzes were conducted. In Figure 4 is possible to observe that the silicon concentration $\left(\mathrm{C}_{[\% \mathrm{Si}}\right)$ on the Y-TZP, regarding the zirconia concentration $\left(\mathrm{C}_{[\% \mathrm{Zr}]}\right)$, decreases as the oxygen concentration increases from 20 to $60 \%$. This is caused by decrease of the film thickness, which contributes to increase the relative concentration of zirconia on the substrate surface. Films deposited at 40 and $60 \%$ have thickness below $150 \mathrm{~nm}$ and as the electron beam in EDS penetrates much more than this value, the results from Figure 4 must be taken only as complementary to the profilometry data, i.e. as thinner the film is, smaller will be the relative concentration of silicon in the film. 


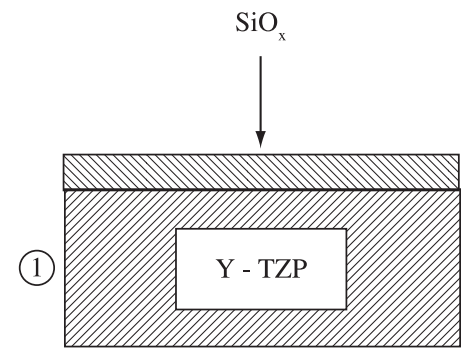

Plastic cylinders

(4)
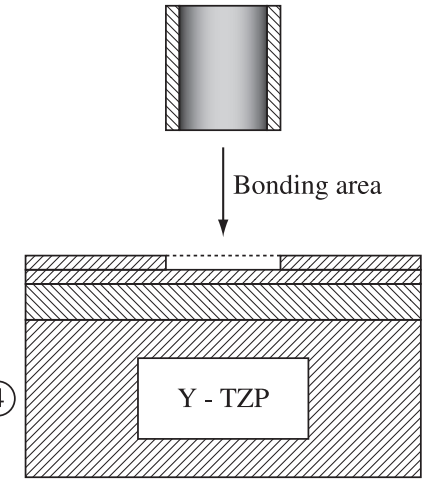

Removing the plastic cylinder

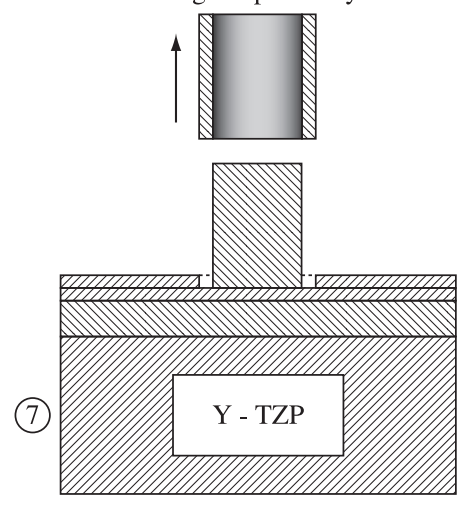

(7)

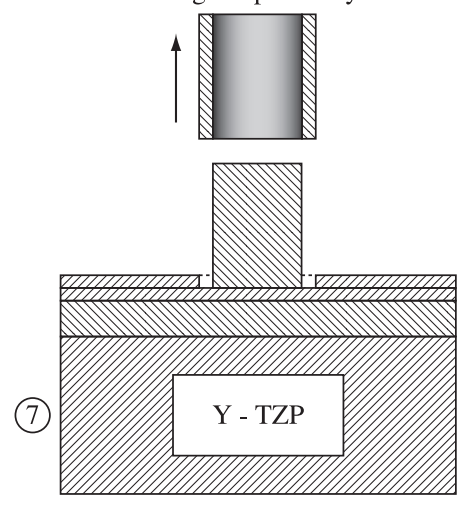

3-methacryloxypropyl trimethoxysilane

(2)

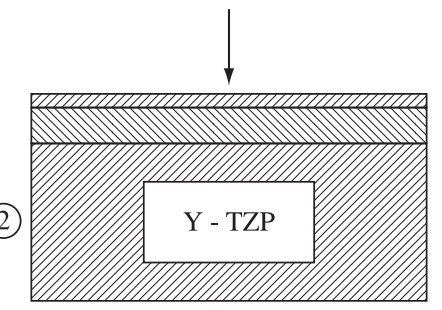

Resin cement

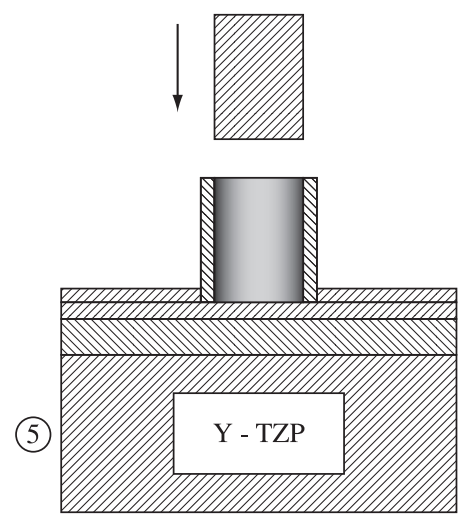

Adhesive tape

(3)

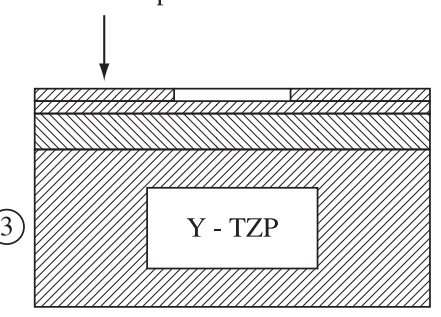

Self-curing resin cement

(48 hours)

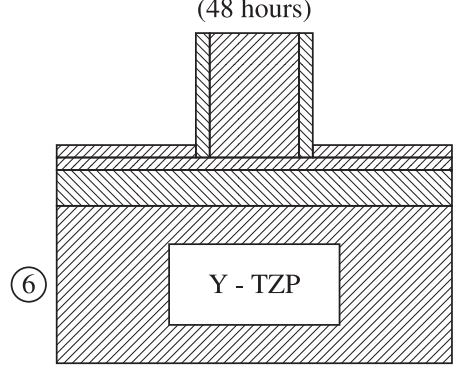

Shear bond strength testing

(8)

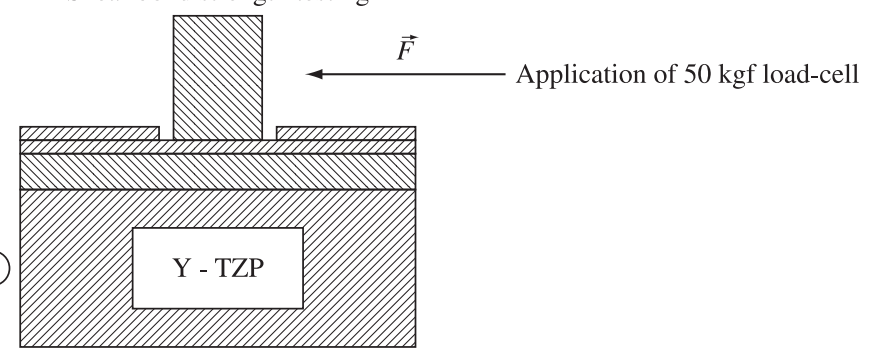

Figure 2. Steps for preparation of the samples used for shear test: 1) $\mathrm{SiO}_{x}$ films deposition on Y-TZP substrate; 2) deposition of 3-methacryloxypropyl trimethoxysilane on $\mathrm{SiO}_{x}$ films; 3) limitation of the bonding area by an adhesive tape; 4) fixation of transparent plastic cylinders; 5) deposition of resin cement into the plastic cylinder; 6) self-curing of resin cement for 48 hours; 7) removing the plastic cylinder and 8) shear test through application of the $50 \mathrm{kgf}$ loadcell on the resin cement. Step (1) was not employed to the sample without $\mathrm{SiO}_{\mathrm{x}}$. Figures are not to scale.

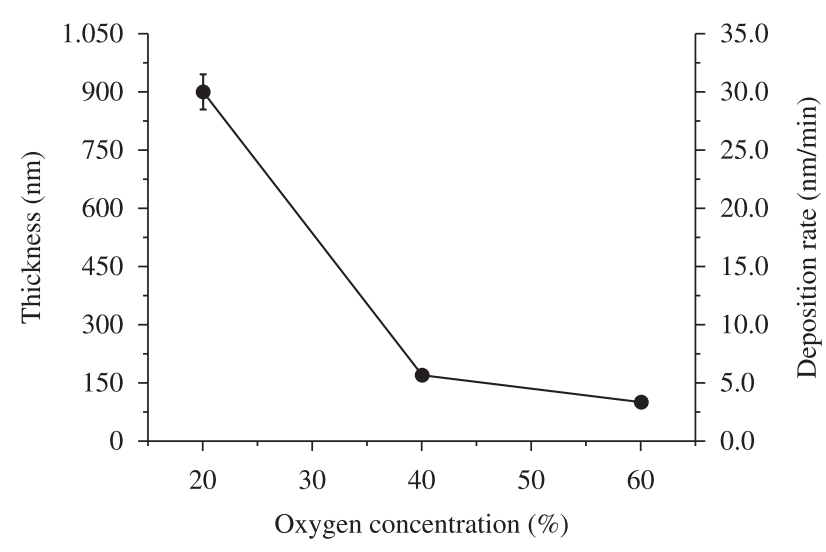

Figure 3. Film thickness and deposition rate of $\mathrm{SiO}_{\mathrm{x}}$ thin films as function of oxygen concentration in the gas discharge.

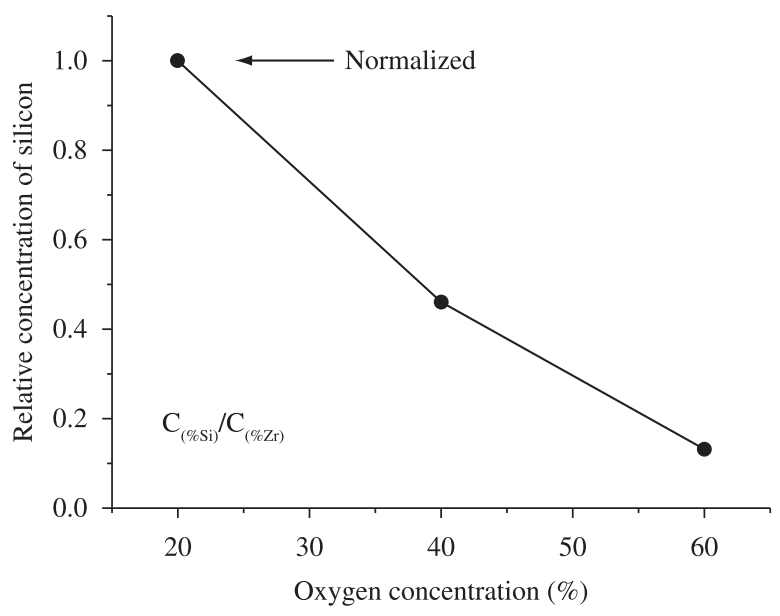

Figure 4. Relative concentration of silicon in the $\mathrm{SiO}_{\mathrm{x}}$ thin films as function of oxygen concentration in the gas discharge. 


\subsection{Shear testing, optical microscopy and scanning electron microscopy (SEM)}

Bond strength decreases from approximately 33 to $15 \mathrm{MPa}$ as the oxygen concentration increases from 20 to $60 \%$, as shows Figure 5. The bond strength without $\mathrm{SiO}_{\mathrm{x}}$ film is $(11.5 \pm 4.5) \mathrm{MPa}$ so that one can observe an interesting increase of the bond strength between Y-TZP and resin cement when $\mathrm{SiO}_{\mathrm{x}}$ film is used as an intermediate adhesive layer. At low oxygen concentrations, the gas discharge is predominantly composed by metallic vapor and argon, which means that at low concentration, Y-TZP surface has a considerable presence of silicon atoms, as described in Figure 4. Thus, the higher bond strength at $20 \% \mathrm{O}_{2}$ may be attributed to the higher presence of silicon on Y-TZP surface ${ }^{15,17}$ that probably makes the silicon oxide grow in a sub-stoichiometric form $(0<x<2)$. This structure is more reactive and has higher chemical affinity to silane in comparison with stoichiometric $\mathrm{SiO}_{2}$. Then, it may be an indicative that the chemical affinity of $\mathrm{SiO}_{x}$ thin films to silane is strongly correlated to the nonstoichiometric form, i.e. the bond strength is higher for $\mathrm{SiO}_{x}$ deposited with $x<2$. Snyders et al. ${ }^{18}$, based on the Berg's model to the modeling of reactive sputter deposition, reported that the oxygen concentration in the gas discharge influences directly the film stoichiometry but more studies regarding this issue must be taken into account in order to evaluate the effect of the film stoichiometry on the bond strength. In addition, at lower oxygen concentrations the plasma sheath in front of the film supports higher potential drop thus more energetic bombardment is promoted by Ar ion flux. This ion impact may cause formation of films with higher roughness, lattice defects and large amount of peaks and valleys ${ }^{12,13}$ where all these effects play an important role to increase the bond strength between Y-TZP and resin cement. On the other hand, as the surface modification by ion bombardment in reactive magnetron sputtering discharges is about of few nanometers ${ }^{13}$, it was not possible to observe significant modifications on the films surface by images of optical profilometry in Figure 6. Although it can be seen that films surface deposited at lower oxygen concentrations (20 and 40\%) are slightly more irregular than film deposited at $60 \% \mathrm{O}_{2}$, which may also explain the increase of the bond strength to the films deposited at low oxygen concentrations.

The increase of the bond strength when zirconia surface is sandblasted with alumina or silica particle associated with zirconia primer is reported elsewhere ${ }^{11,14,16}$ but the deposition of $\mathrm{SiO}_{x}$ thin films between Y-TZP and resin cement as an intermediate adhesive layer has not been studied yet. Although results do not show significant modifications on the surface roughness with deposition of $\mathrm{SiO}_{\mathrm{x}}$ films

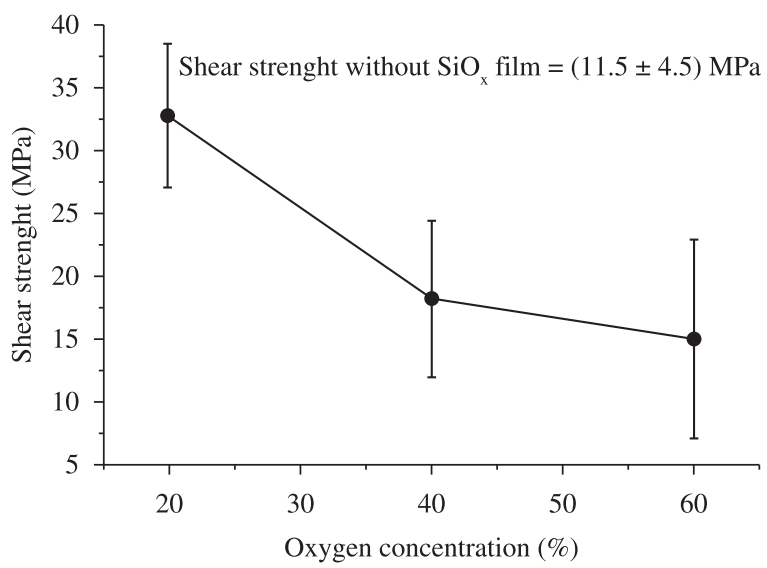

Figure 5. Shear strength between Y-TZP and resin cement as function of the oxygen concentration in the gas discharge. Samples prepared according to the steps of Figure 2. as achieved by sandblasting ${ }^{16}$, this method presents as efficient way to improve the adhesion properties between Y-TZP and resin cement without damage the Y-TZP surface, i.e. the bond strength is based mainly by chemical bond. In addition, this new method increases the bond strength to high values without compromise the quality of the substrate surface, which in traditional methods as, for example, in sandblasting it is not possible. Özcan et al. ${ }^{9}$ evaluated the influence of different surface treatments on the shear bond strength between Y-TZP ceramic surface and resin cement and they found values between 8.23 and $12.02 \mathrm{MPa}$. Blatz et al. ${ }^{14}$ have reported higher values $(20.14 \mathrm{MPa})$ than those reported by Özcan employing air

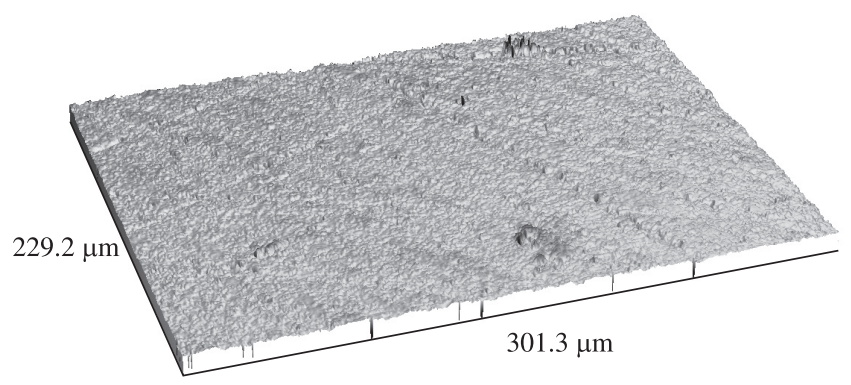

(a)

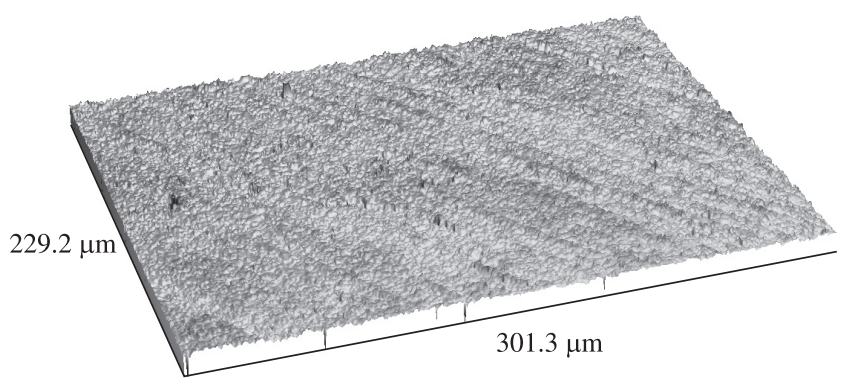

(b)

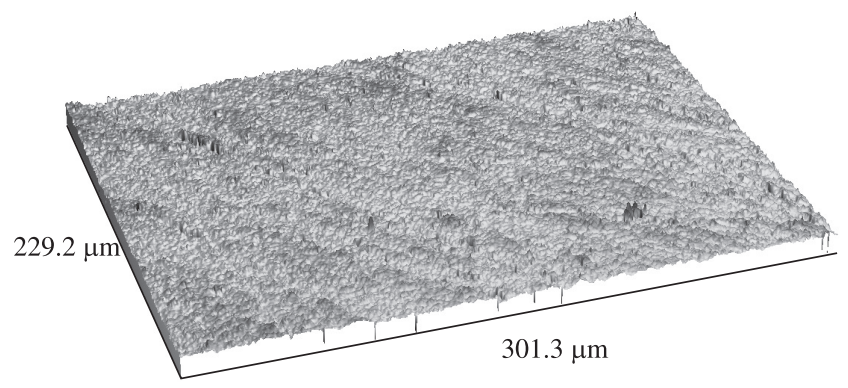

(c)

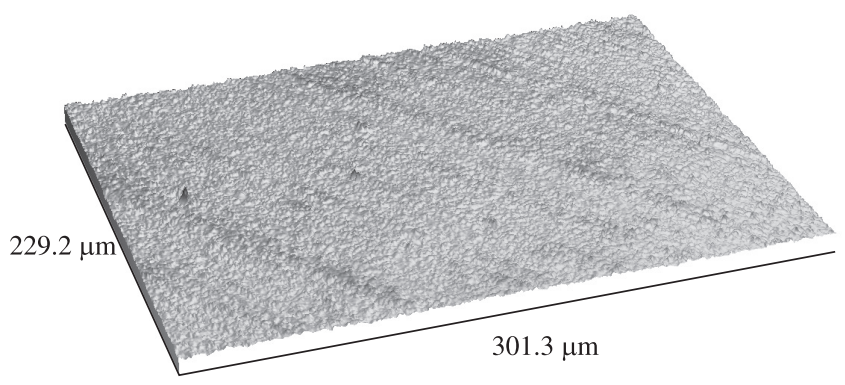

(d)

Figure 6. Images of optical profilometry $(229.2 \times 301.3 \mu \mathrm{m})$ before shear test for a) Y-TZP surface, b) $\mathrm{SiO}_{\mathrm{x}}$ deposited at $20 \% \mathrm{O}_{2}$, c) $\mathrm{SiO}_{\mathrm{x}}$ deposited at $40 \% \mathrm{O}_{2}$ and d) $\mathrm{SiO}_{\mathrm{x}}$ deposited at $60 \% \mathrm{O}_{2}$. 


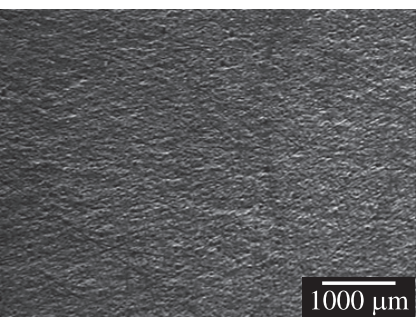

(a)

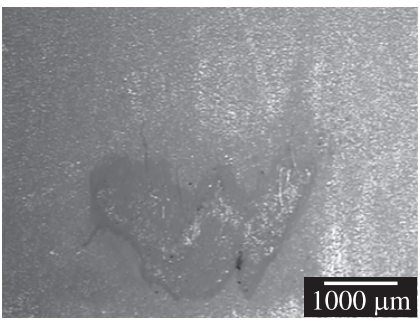

(c)

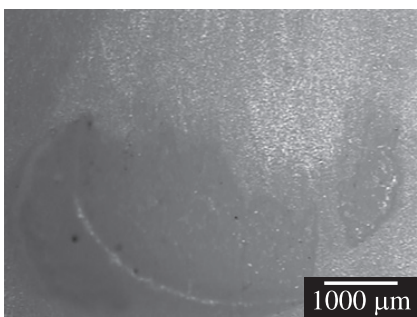

(b)

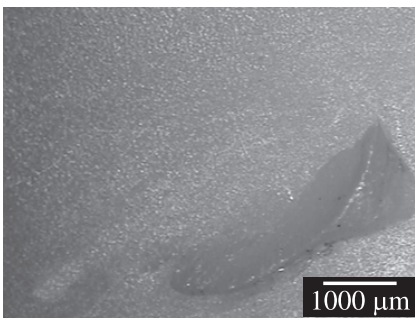

(d)
Figure 7. Images of optical microscopy $(\times 60)$ for fractured samples after shear test: a) Y-TZP surface, b) $\mathrm{SiO}_{\mathrm{x}}$ deposited at $20 \% \mathrm{O}_{2}$, c) $\mathrm{SiO}_{\mathrm{x}}$ deposited at $40 \% \mathrm{O}_{2}$ and d) $\mathrm{SiO}_{\mathrm{x}}$ deposited at $60 \% \mathrm{O}_{2}$.

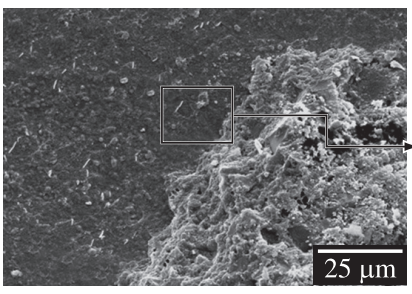

(a)

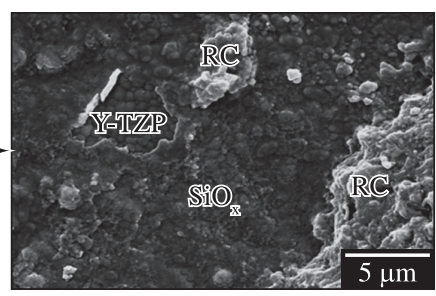

(b)
Figure 8. SEM images a) $\times 1000$ and b) $\times 5000$ for the fractured film after shear test (film deposited at $20 \% \mathrm{O}_{2}$ ). RC means "resin cement".

particle abrasion method with $\mathrm{Al}_{2} \mathrm{O}_{3}$ with $50 \mu \mathrm{m}$ grain size. On the other hand, Nothdurft et al. ${ }^{11}$ using air particle abrasion method with $\mathrm{Al}_{2} \mathrm{O}_{3}$ with $110 \mu \mathrm{m}$ grain size attained values around $25.11 \mathrm{MPa}$. However, all reported data are lower than the bond strength reported in the present study, i.e. lower than $(32.8 \pm 5.4) \mathrm{MPa}$.

In Figure 7(a), optical microscopy without deposition of $\mathrm{SiO}_{x}$ shows adhesive failures between Y-TZP and resin cement while to the others is observed adhesive and cohesive failures. In Figure 8, SEM images to the film deposited at $20 \% \mathrm{O}_{2}$ show adhesive failures between $\mathrm{SiO}_{\mathrm{x}}$ and resin cement, as well as, cohesive fractures of the resin cement and nanospots show adhesive failures between $\mathrm{SiO}_{x}$ and Y-TZP. All these results from Figures 7 and 8 indicate a strong adhesion of the $\mathrm{SiO}_{\mathrm{x}}$ films with the Y-TZP surface and resin cement.

\section{Conclusions}

In this work was studied the bond strength between Y-TZP substrates and resin cement through deposition of $\mathrm{SiO}_{\mathrm{x}}$ thin films between these two materials by reactive magnetron sputtering technique at different oxygen concentrations in the $\mathrm{Ar}+\mathrm{O}_{2}$ plasma forming gas. Results show that $\mathrm{SiO}_{\mathrm{x}}$ films deposited by reactive magnetron sputtering is an efficient and alternative way to improve the bond strength between resin cement and Y-TZP to prosthetic dentistry once deposition of $\mathrm{SiO}_{\mathrm{x}}$ films on Y-TZP increased the bond strength to $(32.8 \pm 5.4) \mathrm{MPa}$ and this value has not been achieved by traditional methods.

\section{Acknowledgements}

Authors would like to thank FAPESP, CNPq and CAPES by financial support and the National Institute for Space Research by profilometry, EDS and SEM measurements.

\section{References}

1. Giordano R. Materials for chairside CAD/CAM-produced restorations. The Journal of the American Dental Association. 2006; 137(1):14S-21S. PMid:16950933

2. Conrad HJ, Seong WJ and Pesun IJ. Current ceramic materials and systems with clinical recommendations: A systematic review. The Journal of Prosthetic Dentistry. 2007; 98(5):389-404. doi:10.1016/S0022-3913(07)60124-3

3. Martin N and Jedynakiewicz NM. Clinical performance of CEREC ceramic inlays: a systematic review. Dental Materials. 1999; 15(1):54-61. doi:10.1016/ S0109-5641(99)00014-7

4. Blatz MB and Swift EJ. Adhesive cementation of high-strength ceramics. Journal of Esthetic and Restorative Dentistry. 2007; 19(5):238-239. PMid:17877619. doi:10.1111/j.1708-8240.2007.00109.x

5. Kitayama S, Nikaido T, Maruoka R, Zhu L, Ikeda M, Watanabe A et al. Effect of an internal coating technique on tensile bond strengths of resin cements to zirconia ceramics. Dental Materials Journal. 2009; 28(4):446-453. PMid:19721282. doi:10.4012/dmj.28.446

6. Piascik JR, Swift EJ, Thompson JY, Grego S and Stoner BR. Surface modification for enhanced silanation of zirconia ceramics. Dental Materials. 2009; 25(9):1116-1121. PMid:19376572. PMCid:2720441. doi:10.1016/j.dental.2009.03.008

7. Derand T, Molin M and Kvam K. Bond strength of composite luting cement to zirconia ceramic surfaces. Dental Materials. 2005; 21(12):1158-1162. PMid:16005508. doi:10.1016/j.dental.2005.02.005

8. Bottino MA, Valandro LF, Scotti R and Buso L. Effect of surface treatments on the resin bond to zirconia-based ceramic. The Journal of Prosthetic Dentistry. 2005; 94(4):369-374. doi:10.1016/j.prosdent.2005.05.011

9. Özcan M, Nijhuis H and Valandro LF. Effect of Various Surface Conditioning Methods on the Adhesion of Dual-cure Resin Cement with MDP Functional Monomer to Zirconia after Thermal Aging. Dental Materials Journal. 2008; 27(1):99-104.

10. Zhang Y, Lawn BR, Malament KA, Thompson VP and Rekow ED. Damage Accumulation and Fatigue Life of Particle-Abraded Ceramics. The International Journal of Prosthodontics. 2006; 19(5):442-448. PMid:17323721

11. Nothdurft FP, Motter PJ and Pospiech PR. Effect of surface treatment on the initial bond strength of different luting cements to zirconia oxide ceramic. Clinical Oral Investigations. 2009; 13(2):229-235. PMid:18758827. doi:10.1007/s00784-008-0222-8

12. Duarte DA, Massi M, Silva Sobrinho AS, Maciel HS, Grigorov K and Fontana LC. Titanium dioxide thin films deposition by direct current hollow cathode magnetron sputtering. The European Physical Journal Applied Physics. 2010; 49:13107. doi:10.1051/epjap/2009179

13. Toku H, Pessoa RS, Maciel HS, Massi M and Mengui UA. The effect of oxygen concentration on the low temperature deposition of $\mathrm{TiO}_{2}$ thin films. Surface and Coatings Technology. 2008; 202(10):2130.

14. Blatz MB, Sadan A, Martin J and Lang B. In vitro evaluation of shear bond strengths of resin to densely-sintered high-purity zirconia-oxide ceramic after long-term storage and thermal cycling. The Journal of Prosthetic Dentistry. 2004; 91(4):356-362. PMid:15116037. doi:10.1016/j.prosdent.2004.02.001

15. Van Hattum ED, Palmero A, Arnoldbik WM and Habraken FHPM. Experimental characterization of the deposition of silicon suboxide films in a radiofrequency magnetron reactive sputtering system. Surface and Coatings Technology. 2004; 188-189:399-403. doi:10.1016/j.surfcoat.2004.08.034

16. Sato H, Yamada K, Pezzotti G, Nawa M and Ban S. Mechanical properties of dental zirconia ceramics changed with sandblasting and heat treatment. Dental Materials Journal. 2008; 27(3):408-414. PMid:18717169. doi:10.4012/dmj.27.408

17. Palmero A, Van Hattum ED, Rudolph $\mathrm{H}$ and Habraken FHPM. Characterization of an $\mathrm{Ar} / \mathrm{O}_{2}$ magnetron sputtering plasma using a Langmuir probe and an energy resolved mass spectrometer. Thin Solid Films. 2006; 494(1-2):18-22. doi:10.1016/j.tsf.2005.07.154

18. Snyders R, Wautelet M, Gouttebaron R, Dauchot JP and Hecq M. Experimental and theoretical study of the role of the gas composition and plasma-surface interactions on the $\mathrm{SnO}_{\mathrm{x}}$ films stoichiometry prepared by DC magnetron reactive sputtering. Thin Solid Films. 2003; 423:125-130. doi:10.1016/S0040-6090(02)01066-0 